\title{
ASSESSMENT OF MEDICAL STUDENTS' KNOWLEDGE AND ATTITUDE TOWARDS BIOBANKS AND BIOSPECIMENS DONATION
}

\author{
Ziady $\mathrm{H}^{(1)}$, El Zeiny $\mathrm{N}^{(1)}$, Sultan $\mathrm{EA}^{(1)}$, El Sharef $\mathrm{Y}^{(2)}$. \\ (1) Community Medicine Department, Faculty of Medicine, University of Alexandria, Alexandria, Egypt, \\ ${ }^{(2)}$ Family Medicine Specialist
}

\begin{abstract}
:
Introduction: Human biobanks are repositories containing biological samples and genetic, medical and other personal data aiming at enhancing understanding of medical conditions for translation into improvements in diagnosis, prevention and treatment. Assessment of the current knowledge and attitudes about biobanks is a prerequisite to tailoring suitable awareness programmes. This type of assessment among future healthcare providers is lacking in Egypt. This crosssectional study was conducted to assess the knowledge and attitude of medical students in Alexandria Faculty of Medicine towards biobanks and biospecimens donation and identify factors influencing their attitude.

Fourth yearmedical studentswho participated in the studywere 570 over a four months period from mid October 2016 till the end of February 2017.Data were collected using a self-administered questionnaire which included demographic and medical data, history of blood donation and participation in research, knowledge about and attitude towards biobanking.

Results showed that less than half $(46.0 \%)$ of the students had heard about the term "biobank", while $71.8 \%$ of them knew the right purpose of a biobank. Less than half of the students (47.2\%) agreed or strongly agreed to donate biospecimens to a biobank. The major reason for positive attitude of students towards donation of biospecimens to a biobank was advancing medical research, benefit the society and future generations while the main reasons for negative attitudewere concerns about confidentiality and misuse of biospecimens in biomedical research.Biospecimen donation willingness was significantly associated with histories of blood donation, hospitalization and participation in health-related research.
\end{abstract}

\section{INTRODUCTION}

The Human Genome Project (HGP)
is an international scientific research
project coordinated by the United
States Department of Energy and the
National Institute of Health. The
project aims at obtaining a fully
connected genetic and physical map
of the human chromosomes and a
complete copy of the nucleotide
sequence of human DNA. As such, it
has been described as the first "big
science" project in biology.
In April 2003 the directories of HGP announced that the first draft of the map of the human genome had been completed. It was anticipated that mapping the complete set of DNA would revolutionize health care and lay the groundwork for the development of clinical markers with predictive capabilities and, thereby, lead to preventive interventions, tailored treatments, and less deaths ${ }^{(2)}$

Human biobanks are repositories containing biological samples and genetic, medical and other personal data. The main purpose of creating biobanks is to link these information sources and making them available for use in research aimed at enhancing our understanding of medical conditions for translation into improvements in diagnosis, prevention and treatment. Largely as a result of these unique features, biobanks also present serious legal, social and ethical challenges that could significantly undermine their potential. $^{(3,4)}$

Biobanks depend on people's willingness to contribute samples for both research and storage. Public support is thus essential in securing the long-term viability of biobanks. ${ }^{(5)}$ Identifying the possible barriers to public participation in biobanking is vital to determining the kinds of biobanks and governance structures that are likely to succeed. Yet researches identifying these barriers are scarce, with only a few studies directly investigating predictors of intention. National surveys from Sweden, Ireland, the UK and the USA all find a range of factors important in determining the willingness to participate, including: perception that the research will be beneficial, general support for medical or genetic research, general trust in researchers, and research organizations, a history of blood donation, increased age, gender, education, experience with a genetic condition and being a parent ${ }^{(6-9)}$

Egyptian scientists have been biobanking human tissue for research purposes for more than 100 years ${ }^{(10)}$, but much can be improved by providing a consistent framework for ethical management. One of the major challenge facing Egyptian biobanks is obtaining informed 
consent, and the lack of a standard method of obtaining such consent. In some areas, researchers record only verbal consent. Abd El-Aal et al. explain that a consent for the use of archival pathology material is almost never obtained. ${ }^{(11)}$

For the past few years, political unrest has disrupted attempts at creating new laws to govern medical research. In addition, inconsistent national laws coupled with conflicting cultural and religious perspectives create further challenges for lawmakers. ${ }^{(10)}$

An initial assessment of the current knowledge and attitudes about biobanks in a targeted geographical area is a prerequisite to tailoring suitable awareness programmes. This type of assessment among medical students - who are future healthcare providers - is lacking in Egypt. Therefore, this study was conducted to assess the knowledge and attitude of medical students in Alexandria Faculty of Medicine towards biobanks and biospecimens donation and to identify factors influencing their attitudeto implement appropriate education and training programmes.

\section{SUBJECTS AND METHODS:}

The cross-sectional design was adopted. The study was conducted in Alexandria Faculty of Medicine, Community Medicine Department on the fourth-year students of the academic year 2016/2017. Three out of four rounds of the fourth academic year 2016/ 2017 were selected then all students in the selected rounds who agreed to respond to the questionnaire were included in the studyThe field work was conducted over about four months period from mid October 2016 till the end of February 2017.

Official approvals for the implementation of the study were obtained from Ethical Committee of the Faculty of Medicine and The Community Medicine Department. Objectives and types of information to be obtained were explained to participant students and their informed consents were taken. Confidentiality of data was ensured.Data werecollected using self-administered questionnaire which included demographic and medical data, history of blood donation and participation in research, knowledge about and attitude towards biobanking.

The questionnaire used for assessment of knowledge and attitude was developed by Merdad et al (12) in their published study who conducted their study among healthcare students at the largest University in Saudi Arabia, King Abdulaziz University (KAU). Structuring of the questionnaire was based mainly on previous conducted surveys then enriched by additional questions. A preliminary phase was conducted to assess validity and reliability of the questionnaire before its use. Initially three Egyptian experts in the field of biomedical research at the faculty were asked to assess the degree to which items in the questionnaires are relevant and can correctly measure the knowledge and attitudes of medical students about biobanking. After that, minimal corrections were done.The next step was pretesting of the questionnaire. We included 30 medical students randomly selected at the faculty. They were asked to fill the questionnaire twice three weeks apart. Data were used to assess internal consistency reliability using cronbach's alpha as well as test retest reliability using intra-class correlation coefficient. The results showed adequate internal consistency reliability (cronbach's alpha $=0.75$ ). Moreover the intra-class correlation coefficient was 0.98 .

Data were analysed using SPSS, version 20.(13)Data are presented as numbers and percentages for categorical variables and means and standard deviations (SD) for continuous variables. For testing associations between qualitative variables, the chi-squared and Monte Carlo tests were used.All results were interpreted at the 5\% level of significance.

\section{RESULTS}

The medical studentswho agreed to participate in the study were 570. Ages of the studied students ranged from 20 to 29 years with a mean age of $21.63 \pm 0.932$ years. More than half $(60 \%)$ of the students were females. Most of the studied students were Egyptians (94.9\%) and other nationalities represented only $5.1 \%$ (table 1 ).

Table (1): Distribution of the studied medical students according to demographic data

\begin{tabular}{|c|c|c|c|}
\hline \multicolumn{2}{|c|}{ Demographic data } & $\mathbf{n}$ & $\%$ \\
\hline \multicolumn{4}{|l|}{ Age (years) } \\
\hline \multicolumn{2}{|c|}{$\begin{array}{ll}\text { - } & \text { Mean } \pm \text { SD } \\
\text { - } & \text { Min - Max }\end{array}$} & \multicolumn{2}{|c|}{$\begin{array}{c}21.63 \pm 0.932 \text { years } \\
20-29 \text { years }\end{array}$} \\
\hline \multirow{2}{*}{ Gender } & - Male & 228 & 40.0 \\
\hline & - Female & 342 & 60.0 \\
\hline \multirow{2}{*}{ Nationality } & - Egyptian & 541 & 94.9 \\
\hline & - Non-Egyptian & 29 & 5.1 \\
\hline \multicolumn{2}{|l|}{ Total } & 570 & 100.0 \\
\hline
\end{tabular}

Medical data of the students areshown in table 2. More than two fifths $(42.6 \%)$ of the students rated their general health as "good", 39.0\% and $11.4 \%$ rated their general health as "very good" and "excellent" respectively. A minority rated their health as "fair" or "poor" (5.8\% and $1.2 \%$ respectively). The majority of the studied students had no chronic diseases, and had no inherited disease in the families $(82.1 \%$ and $70.5 \%$ respectively)and $65.1 \%$ of them had never been hospitalized.

Table 3 demonstrates that more than half $(51.8 \%)$ of the students had donated blood before while nearly three quarters $(74.7 \%)$ of them had never participated in healthrelated research. 
Table (2):Distribution of the studied medical students according to medical data.

\begin{tabular}{llll}
\hline \multicolumn{1}{c}{ Medical data } & & n & \multirow{2}{*}{$\%$} \\
\hline \multirow{2}{*}{ Self-rating ofgeneral health status } & $\bullet$ Excellent & 65 & 11.4 \\
\cline { 2 - 4 } & $\begin{array}{l}\bullet \text { Very } \\
\text { good }\end{array}$ & 222 & 39.0 \\
\cline { 2 - 4 } & $\bullet$ Good & 243 & 42.6 \\
\cline { 2 - 4 } & $\bullet$ Fair & 33 & 5.8 \\
\cline { 2 - 4 } Sufferingfrom any chronic disease & $\bullet$ Poor & 7 & 1.2 \\
\hline \multirow{2}{*}{$\begin{array}{l}* \text { History of inherited disease in the } \\
\text { family }\end{array}$} & $\bullet$ No & 102 & 17.9 \\
\hline \multirow{2}{*}{ History of hospitalization } & $\bullet$ Yes & 168 & 29.5 \\
\cline { 2 - 4 } Total & $\bullet$ No & 402 & 70.5 \\
\hline
\end{tabular}

Table (3): Distribution of the studied medical students according to history of blood donation and participation in research

\begin{tabular}{llll}
\hline $\begin{array}{l}\text { History of blood donation, and participation } \\
\text { in research }\end{array}$ & $\mathbf{n}$ & $\boldsymbol{\%}$ \\
\hline \multirow{2}{*}{ History ofblood donation } & $\bullet$ Yes & 275 & 48.2 \\
\cline { 2 - 4 } & $\bullet$ No & 295 & 51.8 \\
\hline $\begin{array}{l}\text { Participation in health-related } \\
\text { research }\end{array}$ & $\bullet$ Yes & 144 & 25.3 \\
\cline { 2 - 4 } Total & $\bullet$ No & 426 & 74.7 \\
\hline
\end{tabular}

Concerning knowledge of studied students towards biobanking, table 4 shows that $51.4 \%$ heard about the term "Human Genome Project" and less than half (46.0\%) of them had heard about the term "biobank". More than two thirds $(71.8 \%)$ of the students who heard about biobanks knew the right purpose of a biobank which is to collect and store biospecimens for diagnostic, treatment and biomedical research purposes, 9.5\% thought it collects and stores biospecimens for research purposes only, $5.7 \%$ of students thought it collects and stores biospecimens for diagnostic and treatment purposes only, whereas $13 \%$ said they did notknow the purpose of biobanking.

Regarding the meaning of biospecimens according to modern biobanking, $28.6 \%$ of students knew the right meaning which is "samples and/or biomolecules with annotated clinical, socioeconomic and lifestyle data", $12.6 \%$ thought that they were annotated clinical, socioeconomic and lifestyle data only and $11.4 \%$ thought that they were samples and/or biomolecules with annotated clinical data only. On the other hand, $42.5 \%$ did not know what a biospecimen means.

Attitude of the studied students towards biobanking is shown in table 5. Less than half of the students $(47.2 \%)$ agreed or strongly agreed to donate biospecimens to a biobank. On the other hand, only $10.9 \%$ of the students disagreed or strongly disagreed to donate biospecimens to a biobank while $41.9 \%$ were not sure if they are willing to donate biospecimens to a biobank.The majority of the studied students $(81.1 \%)$ had a positive attitude towards medical research and $72.1 \%$ had a positive attitude about genetic research.

As shown in table 6, the major reason for positive attitude of students who agreed and strongly agreed to donate biospecimens to a biobank was that the biobank will advance medical research, benefit the society and future generations (reported by $74.7 \%$ of students). Other reasons included being able to be notified about abnormal results (45.4\%), samples would be collected as part of their medical care $(29.0 \%)$ and they and their families would benefit $(30.5 \%)$ and others $(19.0 \%)$ thought biobanks were already established as core facility of biomedical research in developed countries. A minority of the students $(4.5 \%)$ mentioned other reasons in smaller proportions.

Reasons for negative attitude of the studied students about biobanking are presented in table 7 . The main reasons for negative attitude of students who strongly disagreed and disagreed to donate a biospecimen to a biobank were concerns about confidentiality (33.9\% of students), followed by concern about misuse of biospecimen in biomedical research $(25.8 \%)$. Other reasons included fear of needles/injections (21.0\%), religious reasons (19.4\%), concern that genetic information may be used for discriminatory purposes $(19.4 \%)$, concern about discovering genetic predispositions to some diseases $(17.8 \%)$ and concern that biospecimensmightbe used for commercial purposes $(14.5 \%)$

The relation between different variables and students' attitude towards biobanking is illustrated in table 8. A half $(50.0 \%)$ of the students who rated their general health status as fair or poor agreed or strongly agreed to donate biospecimens compared to $(47.0 \%)$ of those with good, very good or excellent health status. Also, more than half $(52.0 \%)$ of the students who suffered from chronic diseases agreed or strongly agreed to donate biospecimens compared to $46.1 \%$ of those without chronic diseases. However, these differences were statistically insignificant.

Regarding history of hospitalization and its relation to students' attitude towards biobanking, more than half $(51.8 \%)$ of the students with history of hospitalization agreed or strongly agreed to donate compared to (44.8\%) of those who were not hospitalized before. This differencewas statistically significant $(\mathrm{p}=0.015)$.

More than half $(53.8 \%)$ of the students with history of blood donation agreed or strongly agreed to donate biospecimens compared to $(41.1 \%)$ of those who hadnever donated blood. This differencewasstatistically significant $(\mathrm{p}=0.003)$.

More than half $(52.1 \%)$ of the students who previously participated in health-related research agreed or strongly agreed to donate biospecimens compared to $(45.5 \%)$ of those who had never participated in health-related research. This differencewasstatistically significant $(\mathrm{p}=0.048)$. 
Table (4):Distribution of the studied medical students $(n=570)$ according to their knowledge about biobanking.

\begin{tabular}{|c|c|c|c|}
\hline & Knowledge towards biobanking & $\mathbf{n}$ & $\%$ \\
\hline \multirow{2}{*}{$\begin{array}{l}\text { Ever hearing about the term } \\
\text { "Human Genome Project" }\end{array}$} & - Yes & 293 & 51.4 \\
\hline & $\bullet$ No & 277 & 48.6 \\
\hline \multirow{2}{*}{$\begin{array}{l}\text { Ever hearingabout the term } \\
\text { "biobank" }\end{array}$} & - Yes & 262 & 46.0 \\
\hline & $\bullet$ No & 308 & 54.0 \\
\hline
\end{tabular}

- Collect and store biospecimens for diagnostic and treatment purposes

The purpose of a "biobank" $(n=262)$

- Collect and store biospecimens for research purposes only

- Collect and store biospecimens for diagnostic, treatment and biomedical research purposes*

- Do not know

\begin{tabular}{llcc} 
& $\bullet$ Do not know & 34 & 13.0 \\
\hline & $\bullet$ Samples and/or biomolecules only & 28 & 4.9 \\
\cline { 2 - 4 } Biospecimens & $\bullet$ Samples and/or biomolecules with annotated clinical data only & 65 & 11.4 \\
\cline { 2 - 4 } $\begin{array}{l}\text { meaningaccording to modern } \\
\text { biobanking }\end{array}$ & $\begin{array}{l}\bullet \text { Samples and/or biomolecules with annotated clinical, socioeconomic } \\
\text { and lifestyle data }\end{array}$ & 163 & 28.6 \\
\cline { 2 - 4 } & $\bullet$ Annotated clinical, socioeconomic and lifestyle data only & 72 & 12.6 \\
\cline { 2 - 4 } & $\bullet$ Do not know & 242 & 42.5 \\
\hline
\end{tabular}

* The right answer

Table (5):Distribution of the studied medical students according to their attitude towards biobanking

\begin{tabular}{|c|c|c|c|}
\hline \multicolumn{2}{|c|}{ Attitude towards biobanking } & \multirow{2}{*}{$\begin{array}{l}\mathbf{n} \\
63 \\
\end{array}$} & \multirow{2}{*}{$\begin{array}{c}\% \\
11.1 \\
\end{array}$} \\
\hline \multirow{5}{*}{$\begin{array}{l}\text { Willing to donate a biospecimen* to a } \\
\text { biobank in order to perform } \\
\text { biomedical research }\end{array}$} & - strongly agree & & \\
\hline & - agree & 206 & 36.1 \\
\hline & - Not sure & 239 & 41.9 \\
\hline & - Disagree & 44 & 7.7 \\
\hline & - $\quad$ strongly disagree & 18 & 3.2 \\
\hline \multirow{5}{*}{$\begin{array}{l}\text { Havinga positive attitude towards medical } \\
\text { research }\end{array}$} & - strongly agree & 167 & 29.3 \\
\hline & - agree & 295 & 51.8 \\
\hline & - Not sure & 84 & 14.7 \\
\hline & - Disagree & 21 & 3.7 \\
\hline & - strongly disagree & 3 & 0.5 \\
\hline \multirow{5}{*}{$\begin{array}{l}\text { having a positive attitude towards genetic } \\
\text { research }\end{array}$} & - strongly agree & 149 & 26.1 \\
\hline & - agree & 262 & 46.0 \\
\hline & - Not sure & 128 & 22.4 \\
\hline & - Disagree & 29 & 5.1 \\
\hline & - $\quad$ strongly disagree & 2 & 0.4 \\
\hline Total & & 570 & 100.0 \\
\hline
\end{tabular}

* e.g. blood, urine, tissue, buccal swap, toe nail, hair 
Table (6): Distribution of the studied medical students who had positive attitude about biobanking according to their mentioned reasons

\begin{tabular}{|c|c|c|}
\hline Reasons for positive attitude $(n=269)^{*}$ & $\mathbf{n}^{* *}$ & $\%$ \\
\hline - The biobank will advance medical research, benefit the society and future generations & 201 & 74.7 \\
\hline - $\quad$ My family and I will benefit & 82 & 30.5 \\
\hline - I could be notified about abnormal results & 122 & 45.4 \\
\hline - Samples would already be collected as part of my medical care & 78 & 29.0 \\
\hline - Biobanks are already established as core facility of biomedical research in developed countries & 51 & 19.0 \\
\hline - $\quad$ Other & 12 & 4.5 \\
\hline
\end{tabular}

*Only those who agreed and strongly agreed are included, total $=>100 \%$ as more than one answer could be selected.

** categories are not mutually exclusive

Table (7): Distribution of the studied medical students who had negative attitude about biobanking according to their mentioned reasons

\begin{tabular}{|c|c|c|}
\hline Reasons For negative attitude $(n=62)^{*}$ & $\mathbf{n}^{* * *}$ & $\%$ \\
\hline - Concern about misuse of biospecimens in biomedical research & 16 & 25.8 \\
\hline - Concern about discovering genetic predispositions to some diseases & 11 & 17.8 \\
\hline - Concern about confidentiality & 21 & 33.9 \\
\hline - Concern that genetic information mightbe used for discriminatory purposes & 12 & 19.4 \\
\hline - Concern that biospecimensmightbe used for commercial purposes & 9 & 14.5 \\
\hline - $\quad$ Fear of needles/injections & 13 & 21.0 \\
\hline - Religious reasons & 12 & 19.4 \\
\hline - $\quad$ Other & 4 & 6.5 \\
\hline
\end{tabular}

* Only those who strongly disagreed and disagreed are included, total $=>100 \%$ as more than one answer could be selected.

** categories are not mutually exclusive 


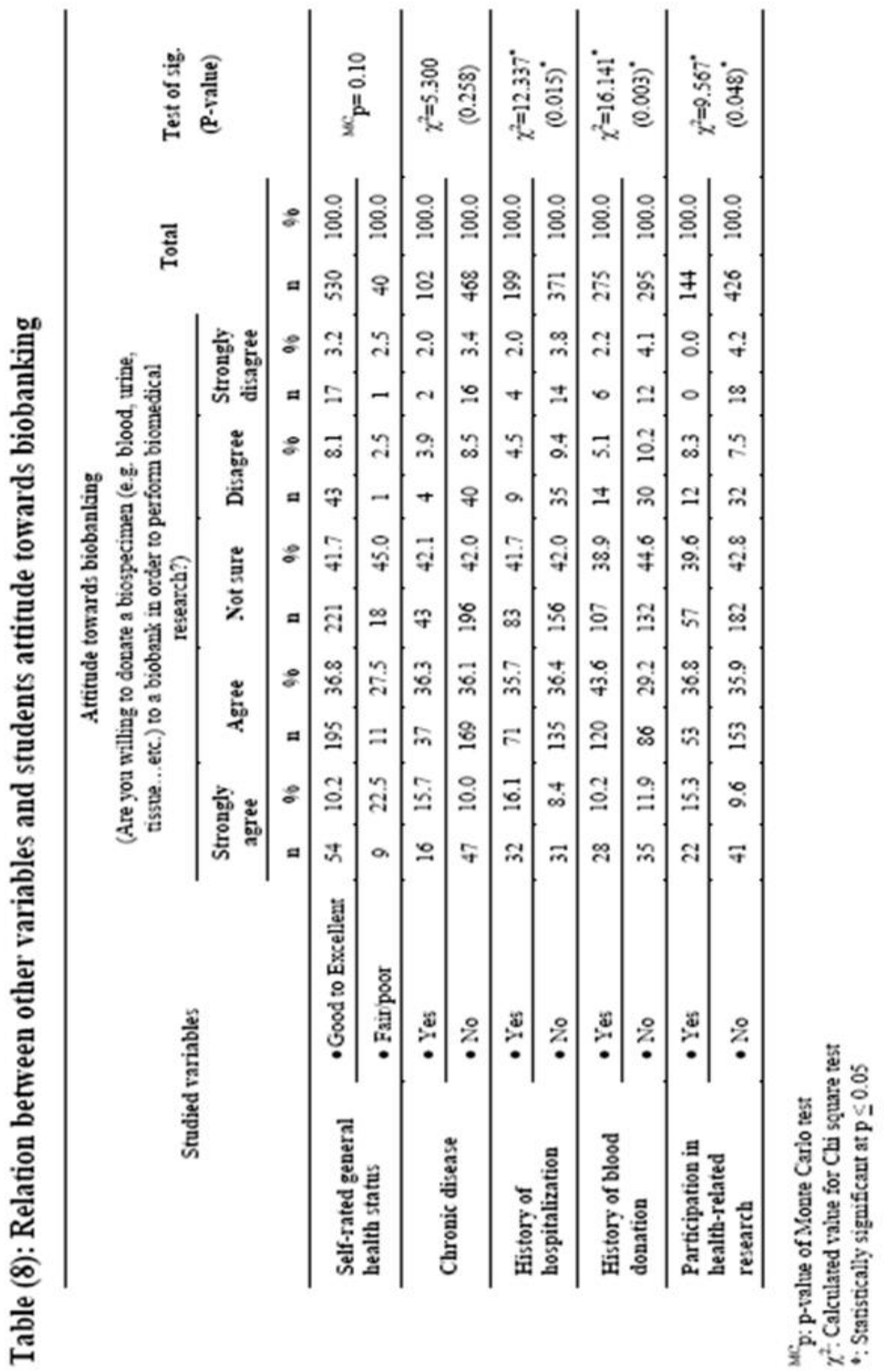




\section{DISCUSSION}

The rapid development of biotechnological research has stimulated the development of biobanks that store biological samples and allow for identification of disease genes, which could lead to more personalized health prevention programmes and treatments. Combining health and genetic data from large populations also means that the complex relationships between genes, environment and disease can be explored. ${ }^{(14,15)}$

An initial assessment of the current knowledge and attitudes about biobanks in a targeted geographical area is a prerequisite to tailoring suitable awareness programmes for the public or general medical students. This type of assessment among medical students - who are future healthcare providers - is lacking in Egypt. Therefore, this study, to our knowledge, is the first in Egypt to assess the knowledge of medical students about biobanks, their willingness to donate biospecimens and the determinants of these attitudes to implement appropriate education and training programmes.

Results of this study revealed that medical students lacked sufficient knowledge about biobanks, as about half of them had never heard of the term "biobank", or the "HGP" - the largest megaproject in biology in the last century which has laid the foundation for several international collaborative and multidisciplinary initiatives to date $e^{(16)}$

Interestingly, and despite the noticeable lack of knowledge about the HGP and biobanks, findings of this study demonstrated that $47.2 \%$ of students were willing to donate biospecimens to biobanks. Willingness of medical students at Alexandria University to donate biospecimens is in agreement with previous findings from another survey conducted among the general public in Jordan 2012, a neighbouring country with a similar culture, were less than two thirds $(63.8 \%)$ were willing to donate biospecimens to biobanks.(17) Another study was conducted in Saudi Arabia 2011 on outpatients clinics where expected to be less aware of the HGP and biobanking; however, $70.1 \%$ of participants were willing to donate specimens. ${ }^{(18)}$

Several studies have investigated factors related to the willingness to donate to biobanks. Our data analysis indicated that such biospecimen donation willingness was significantly associated with histories of blood donation, hospitalization and participation in health-related research. However, in a study targeting Saudi outpatients with a previous history of tissue tests and/or donation, the percentage willing to donate biospecimens was only approximately $9.0 \%{ }^{.(18)}$ This conspicuous difference might be because the study of viewers consisted of medical students, who were therefore aware of the importance of voluntary blood donations for enhancing both biomedical research and clinical practice.

To ensure suitable decision-making and customized awareness in medical students, an assessment of their knowledge and attitudes about biobanks and biomedical research was necessary' ${ }^{(19)}$ In fact, the findings of the current study revealed that student knowledge of

biobanking and biospecimens was insufficient, where $71.8 \%$ could correctly define the purpose of biobanks, and $28.6 \%$ were able to determine the correct definition of biospecimens. This knowledge score was expected, as less than half $(48.6 \%)$ of students had heard about the HGP, and $46.0 \%$ had heard of the term "biobank" as mentioned earlier. A study conducted among members of Kaiser Permanente in Colorado members who were approached in clinical waiting rooms found that the majority $(85.0 \%)$ of these patientsanswered correctly when they were asked about general information regarding biospecimen collection for research purposes. This high percentage was attributed to the brochures and a draft consent form that were distributed to the respondents prior to answering the survey. $\left({ }^{20)}\right.$

Regarding the factors related to willingness to donate biospecimens, the present study demonstrated that participants' belief that "biobanks will advance medical research and benefit society and future generations" was the major factor influencing this willingness (74.7\%). Several studies worldwide addressed these factors.(20-24) A study conducted in 2014 with Michigan college students found that $78 \%$ of them were very supportive of donating, hoping that it would benefit future patients. ${ }^{.(25)}$

On the other hand, the main reasons participants in the current study were not willing to donate were concerns about confidentiality (33.9\%) and misuse of biospecimens and fear of needles/injections (21.0\%). Other respondents reported concerns about discovering genetic predispositions to some diseases $(19.4 \%)$, and these concerns could be influenced by the relatively high rate of consanguinity in Arab countries.(26,27) Concerns about confidentiality have also been stated to be a main reason for refusing to donate in other studies elsewhere and were highlighted by other scientists and medical healthcare providers as evidence of the importance of building "trust" with the public.(19,20,28-33) Other studies in neighbouring countries have reported that $16 \%$ of medical students in Turkey (2015) were not willing to donate biospecimens for religious reasons, whereas in a Jordanian study (2014), $61 \%$ of the studied population correlated their biospecimen donations with religious permission $^{.(34,35)}$

\section{CONCLUSION}

The results of our study show that there was a shortage in knowledge of students in relation to Human Genome Project, biobanks and biospecimens. Although most of the students had positive attitudes towards medical and genetic research, less than half of them had positive attitude towards donation of biospecimens to a biobank. The major reason for positive attitude of students was that the biobank will advance medical research, benefit the society and future generations while the main reasons for 
negative attitude were concerns about confidentiality followed by concern about misuse of biospecimen in biomedical research.

History of inherited disease had a significant effect on knowledge and attitudes related to biobanks and donation of biospecimens, while history of blood donation, history of hospitalization and previous participation in healthrelated research significantly improved the attitude of students towards donating biospecimens to biobanksin order to perform biomedical research.

It is recommended that Alexandria Faculty of Medicine needs to raise awareness of medical students and improve their knowledge and attitude towards biobanking. This could be achieved through including the topic in undergraduate medical curriculum and organizing relevant seminars and workshops. Moreover, Alexandria Medical staff should encourage students to participate in health related research as this improves their attitude towards biospecimen donation.

Further studies are recommended to assess knowledge and attitude of medical staff on biobanks and biospecimen donation. According to the results of these studies more medical groups may be included in the programmes designed to improve knowledge and attitude related to biobanks and biospecimen donation

Funding: None.

Competing interests: None declared.

\section{REFERENCES}

1. National Human Genome Research Institute, International Human Genome Sequencing Consortium. International Consortium Completes Human Genome Project: All Goals Achieved, New Vision for Genome Research Unveiled. 2003. Available at: http:// www. genome.gov/ 11006929.

2. Collins FS, Green ED, Guttmacher AE, Guyer MS. A vision for the future of genomics research. Nature 2003; 422: 835-47.

3. Knoppers B, Chadwick R. Human genetic research: emerging trends in ethics. Nat Rev Genet 2005; 6: 75-9.

4. Cambon-Thomsen A, Rial-Sebbag E, Knoppers B. Trends in ethical and legal frameworks for the use of human biobanks. Eur Respir J 2007; 30: 373-82.

5. Tutton R, Kaye J, Hoeyer K. Governing UK. Biobank: the importance of ensuring public trust. Trends Biotechnol 2004; 22: 284-5.

6. Kettis-Lindblad A, Ring L, Vibirth E, Hansson M. Genetic research and donation of tissue samples to biobanks. What do potential sample donors in the Swedish general public think? Eur J Public Health 2005; 15: 1-8.

7. Cousins G, McGee H, Ring L, Conroy R, Kay E. Public perceptions of biomedical research: a survey of the general population in Ireland. Health Research Board: Health Services Research Centre, Royal College of Surgeons in Ireland, 2005.

8. Webster A, Brown N, Douglas C, Lewis G. Public attitudes to third party access and benefit sharing: their application to UK Biobank (Final Report). UK Biobank
Ethics and Governance Council. 2008. Available at: http://www. egcukbiobank.org.uk/assets/wtx052208.pdf.

9. McQuillan GM, Porter KS, Agelli M, Kington R. Consent for genetic research in a general population: The NHANES experience. Genet Med 2003; 5: 35-42.

10. Biobanking: international norms. Knoppers BM. J Law Med Ethics 2005; 33: 7-14.

11. Abd El-Aal WE, Abaas NF, El-Sharkawy SL, Badawi MA. Biobanking: A challenge facing pathologists in Egypt. Br J Med Med Res 2016; 13: 1-10.

12. Merdad L, Aldakhil L, Gadi R, Assidi M, Saddick SY, Abuzenadah A, et al. Assessment of knowledge about biobanking among healthcare students and their willingness to donate biospecimens. BMC Med Ethics 2017;18(1):32.

13. Kirkpatrick LA and Feeney BC. A simple guide to IBMSPSS statistics for version 20.0. studented. Bemont, Calif: Wadsworth, Cengage Learning; 2013.

14. Kaiser J. Biobanks. Population databases boom, from Iceland to the U.S. Science 2002; 298: 1158-61.

15. Burton JL, Wells M. The Alder Hey affair. Arch Dis Child 2002; 86: 4-7.

16. Green ED, Watson JD, Collins FS. Human genome project: twenty-five years of big biology. Nature. 2015;526(7571):29-31.

17. Ahram M, Othman A, Shahrouri M. Public perception towards biobanking in Jordan. Biopreserv Biobank. 2012;10(4):361-5.

18. Al-Jumah M, Abolfotouh MA, Alabdulkareem IB, Balkhy HH, Al-Jeraisy MI, Al-Swaid AF, Al-Musaaed EM, Al-Knawy B. Public attitude towards biomedical research at outpatient clinics of King Abdulaziz Medical City, Riyadh, Saudi Arabia. East Mediterr Health J. 2011;17(6):536-45.

19. Feero WG, Green ED. Genomics education for health care professionals in the 21 st century. JAMA. 2011;306(9):989-90.

20. Rahm AK, Wrenn M, Carroll NM, Feigelson HS. Biobanking for research: a survey of patient population attitudes and understanding. J Community Genet. 2013;4(4):445-50.

21. Dry SM, Garrett SB, Koenig BA, Brown AF, Burgess MM, Hult JR, Longstaff H, Wilcox ES, Madrigal Contreras SK, Martinez A, Boyd EA, Dohan D. Community recommendations on biobank governance: Results from a deliberative community engagement in California. PLoS One. 2017;24;12(2):e0172582.

22. Porteri C, Pasqualetti P, Togni E, Parker M. Public's attitudes on participation in a biobank for research: an Italian survey. BMC Med Ethics. 2014;15-81.

23. Henneman L, Vermeulen E, van El CG, Claassen L, Timmermans DR, Cornel MC. Public attitudes towards genetic testing revisited: comparing opinions between 2002 and 2010. Eur J Human Genet. 2013;21(8):793-9.

24. Simon CM, L'Heureux J, Murray JC, Winokur P, Weiner G, Newbury E, Shinkunas L, Zimmerman B. Active choice but not too active: public perspectives on biobank consent models. Genet Med. 2011;13(9):821-31.

25. Platt T, Platt J, Thiel DB, Fisher N, Kardia SL. 'Cool! and creepy': engaging with college student stakeholders in Michigan's biobank. J Commun Genet. 2014; 5(4): 349-62. 
26. Abu-Elmagd M, Assidi M, Schulten HJ, Dallol A, Pushparaj P, Ahmed F, Scherer SW, Al-Qahtani M. Individualized medicine enabled by genomics in Saudi Arabia. BMC Med Genom. 2015;8 Suppl 1:S3.

27. Turki RF, Assidi M, Banni HA, Zahed HA, Karim S, Schulten HJ, Abu-Elmagd M, Rouzi AA, Bajouh O, Jamal HS, et al. Associations of recurrent miscarriages with chromosomal abnormalities, thrombophilia allelic polymorphisms and/or consanguinity in Saudi Arabia. BMC Med Genet. 2016;17 Suppl 1:69.

28. Goddard KA, Smith KS, Chen C, McMullen C, Johnson C. Biobank recruitment: motivations for nonparticipation. Biopreserv Biobank. 2009;7(2):119-21.

29. Moodley K, Singh S. "It's all about trust": reflections of researchers on the complexity and controversy surrounding biobanking in South Africa. BMC Med Ethics. 2016;17(1):57.

30. Vayena E, Gasser U. Between openness and privacy in genomics. PLoS Med. 2016;13:1.
31. Erlich Y, Williams JB, Glazer D, Yocum K, Farahany N, Olson M, Narayanan A, Stein LD, Witkowski JA, Kain RC. Redefining genomic privacy: trust and empowerment. PLoS Biol. 2014;12(11):e1001983.

32. Zarate OA, Brody JG, Brown P, Ramirez-Andreotta MD, Perovich L, Matz J. Balancing benefits and risks of immortal data: participants' views of open consent in the personal genome project. Hastings Cent Rep. 2016;46(1):36-45.

33. L'Heureux J, Murray JC, Newbury E, Shinkunas L, Simon CM. Public perspectives on biospecimen procurement: what biorepositories should consider. Biopreserv Biobank. 2013;11(3):137-43.

34. Sagiroglu M, Gunay O, Balci E. Attitudes of Turkish medical and law students towards the organ donation. Int J Organ Transplant Med. 2015;6(1):1-7.

35. Ahram M, Othman A, Shahrouri M, Mustafa E. Factors influencing public participation in biobanking. Eur J Human Genet. 2014;22(4):445-51 